\title{
Brand engagement in self-concept: A comparative study in Austria, Italy and Poland
}

Wiktor Razmus Institute of Psychology, The John Paul II Catholic University of Lublin,

\section{Lublin, Poland}

Valentina Mazzoli School of Economics and Management, Università degli Studi di Firenze, Florence, Italy

Diletta Acuti Department of Marketing, University of Portsmouth, Portsmouth, UK Sonja Grabner-Kräuter Department of Marketing and International Management, AlpenAdria-Universitat Klagenfurt, Klagenfurt, Austria

\begin{abstract}
Purpose: The aim of this article is to shed light on cross-country comparisons of brand engagement in self-concept (BESC) among consumers from European countries and to link presumed differences with country-level economic growth and materialism. This study contributes to the literature on customer-brand relationship and provides implications for international branding strategies.

Design/methodology/approach: This observation study explored levels of BESC in three European countries. Questionnaire data was collected from consumers of Austria $(N=302)$, Italy $(N=431)$, and Poland $(N=410)$ with the purpose to make cross-country comparisons of BESC among consumers.

Findings: The results provide evidence for partial scalar invariance of the BESC scale. Crosscountry comparisons of latent means reveal that Polish consumers score higher on BESC than consumers from Austria and Italy. Moreover, Austrian consumers score higher on BESC than Italian consumers.
\end{abstract}


Research limitations/implications: Culture as a contextual factor of BESC should be studied further. The findings should be replicated with non-convenience samples in additional cultural contexts in order to improve the generalizability of data. SEM could be used to investigate psychological drivers of BESC differences.

Practical implications: The findings coming from the cross-country comparisons of BESC are of practical relevance to marketing managers: they should tailor their branding and communication strategies accordingly.

Originality/value: So far, the understanding of cross-cultural and cross-country differences in consumer-brand relationships has remained limited. This study adopts a rigorous approach to cross-cultural research enriching the literature on BESC from a cross-country perspective.

Keywords: brand engagement, self, cross-country differences, consumer behaviour, BESC 


\section{Introduction}

The notion that brands become part of consumers' extended selves has been well established in the psychological and marketing literature (Escalas and Bettman, 2003; Lisjak et al., 2012; Reimann et al., 2012). Research on the extended self is one of the trends of studies of consumer-brand relationships (Fetscherin and Heinrich, 2015). Increasing interest in this field was observed after 2010, when the Marketing Science Institute (MSI, 2010) included consumer engagement among the priority research directions for the future. Researchers have developed and introduced a number of different constructs describing diverse relationships with brands (Fetscherin and Heinrich, 2015). Among these which have received the most attention are self-brand connections - the extent to which individuals have incorporated brands into their self-concept (Escalas, 2004; Escalas and Bettman, 2003), consumer-brand identification - a consumer's "state of oneness with a brand" (StokburgerSauer et al., 2012), and customer brand engagement - how customers could cognitively valence and emotionally and/or behaviorally react toward all brand activities (Hollebeek, 2011). All of these constructs aim to measure relationships between a consumer and a particular brand. In contrast, brand engagement in self-concept (BESC) is defined as a consumer's general propensity to include important brands as part of the self-concept (Sprott et al., 2009). Thus, BESC is a characteristic of a single individual that can affect the relationship with brands. This construct represents a generalized view of brands in relation to the self (not brand specific), and it comprehensively reflects reality since consumers can integrate many different brands into their self-concept.

Research on BESC shows that consumers construe their self-concepts in terms of their favourite brands and that such construal can have significant implications for marketers in terms of brand equity (Keller, 1993), attention to brands (Sprott et al., 2009) and brand preference (Liu et al., 2018). Indeed, consumers tend to define themselves by engaging with 
brands in public or in private (Ferraro et al., 2011). For this reason, the retail clothing industry, as one example, designs and formulates a large-scale communication strategy using self-concept as the denominator for building corporate brands and attracting new customers (Mazzoli et al., 2019). As another example, consumers are also likely to use precious jewellery brands to enhance their self-image while treating the jewellery as a very special personal belonging (Jamal and Goode, 2001).

Previous research on BESC has focused mainly on the marketing consequences of this phenomenon (Alden et al., 2016; Flynn et al., 2016; Goldsmith et al., 2011, 2012; Liu et al., 2018). Recently BESC has also been analysed from a psychological perspective (Liu and Minton, 2018; Razmus et al., 2017). Consistent with the growing research on consumer-brand relationships (Fetscherin and Heinrich, 2015; Islam and Rahman, 2016) there has been renewed interest in cross-cultural and cross-country studies that could provide insight into differences and similarities in these constructs among people from various countries. Understanding the impact of national culture on consumer behaviours is essential for succeeding in international marketing (Solomon et al., 2010). To date, there is only one crosscultural study that has compared BESC levels of U.S. consumers and Asian consumers (Flynn et al., 2013). In this regard it is worth mentioning that a systematic review of research on diverse consumer-brand relationships found that most of the research came from the U.S., Australia and New Zealand (Islam and Rahman, 2016). As a result, understanding of the cross-cultural and cross-country differences in BESC remains limited. Another research gap concerns the extent to which BESC depends on the socio-economic context of the individual consumer.

To address these research gaps, this study aims to explore differences in BESC among consumers from three European countries (i.e., Austria, Italy, and Poland) and to link presumed differences with country-level economic growth and materialism as indicators of 
the socio-economic situation in these countries. In doing so, our paper makes several contributions to the research on consumer-brand relationships from a cross-cultural perspective. First, the authors who developed the BESC construct did not specify the relationship between this individual tendency and socio-economic and situational factors. Our research brings new knowledge by analysing the socio-economic context of consumer-brand relationships, in particular BESC. Second, in contrast to previous research, we move beyond examining BESC in the U.S. context (Flynn et al., 2013; Goldsmith et al., 2011; Liu et al., 2018; Sprott et al., 2009) to shed light on comparisons among consumers from three different European Union (EU) member countries. Indeed, even geographically close countries such as European countries reveal differences featuring customer-brand relationships (e.g. Hakala et al., 2012). Thus, it is important to focus both on differences and similarities of customerbrand relationships to contribute to the body of knowledge about consumer behaviours in the context of global consumption (e.g. Alden et al., 2016; Strizhakova et al., 2008, 2011;

Wallström et al., 2010). In so doing, this study investigates the tendency of consumers living in specific European countries to develop strong relationships with brands highlighting differences and similarities across countries. The development of insight into this area can be useful for managerial practitioners, as well as for future research in this field. Third, we offer a more rigorous approach to cross-cultural research, which requires testing of measurement invariance before mean comparisons (Steenkamp and Baumgartner, 1998). In previous research, when BESC levels were compared between U.S. and South Korean consumers (Flynn et al., 2013), measurement invariance was not tested. Our study meets the requirements for rigorous cross-cultural research according to which the results of comparisons are meaningful only if at least partial scalar measurement invariance is proved (Steenkamp and Baumgartner, 1998).

\section{Brand engagement in self-concept}


Over the past twenty years, branding research has paid increasing attention to several forms of customer-brand relationships (e.g., Aaker et al., 2004; Fournier, 1998), such as selfbrand connection (Escalas, 2004; Tan et al., 2019), brand love (Batra et al., 2012) and brand attachment (Whan Park et al., 2010). More recently, many scholars have investigated the concept of brand engagement (e.g., Brodie et al., 2011; Hollebeek, 2011), focusing their efforts on defining the construct with its drivers and consequences and developing its measures. Brand engagement is defined as "the level of an individual customer's motivational, brand-related and context-dependent state of mind characterised by specific levels of cognitive, emotional and behavioural activity in direct brand interactions" (Hollebeek, 2011, p. 790). However, other specifications of brand engagement have been developed.

Among the others, the concept of brand engagement in self-concept (BESC), developed by Sprott, Czellar, and Spangenberg (2009), has attracted considerable attention. BESC is defined as “an individual difference representing consumers' propensity to include important brands as part of how they view themselves"(Sprott et al., 2009, p. 92). The theoretical background of this idea is the cognitive schema theory, in which the self is understood as a set of schemas representing a stable structure of knowledge (Markus, 1977). Individuals show different self-schemas, and these differences lead to various attitudes and behaviours towards objects relevant to these schemas, such as brands. Thus, this work builds on the established view that the self can organize and maintain brands as part of the selfschema and associated memory structures (Keller, 1993; Liu et al., 2018). In other words, BESC demonstrates how important brands are to consumers' self-schemas (Alden et al., 2016). It is worth noting that self-schemas are shaped by culture, and shape culture (Markus and Kitayama, 1991, 2010). This may mean that BESC as individual tendency will also depend on culture or socio-economic context. Indeed, according to Markus and Kitayama's 
Self Construal Theory (1991), culture determines self-construal and individuals from different cultures have reliable differences in self-construal (e.g., Jakubanecs et al., 2019).

Experimental studies have shown that consumers construe their self-concepts in terms of favourite brands, and such a construal can have important implications for marketers (Liu and Minton, 2018). As already shown by Sprott's team (2009), BESC is significantly related to stronger memory associations between the self and favourite brands and to better recall of the names of current branded possessions. Additionally, BESC leads consumers to pay more attention to brands in incidental brand exposure. Finally, consumers with higher levels of BESC show greater brand loyalty since they prefer higher-priced products and show willingness to wait longer for new products introduced by their favourite brands. The findings of more recent studies have shown that consumers with high BESC tendencies interact more on brand websites (Alden et al., 2016). In addition, consumers with higher levels of BESC prefer national to private brands (Liu et al., 2018) and become enthusiastic advocates of the brand (Samala and Singh, 2018).

Whereas studies of the marketing consequences of BESC have been undertaken by scholars from various countries, there is a dearth of research exploring cross-country differences in BESC itself. Recognition of such differences between countries will allow to further develop the BESC concept by considering socio-economic determinants, which have not been captured so far. Such research is critical to developing and testing theoretical frameworks of BESC in the global context. Understanding differences in BESC between countries could also help companies better understand consumer-brand relationships in various country markets and apply appropriate strategies in the global marketplace. Indeed, differently from other brand-related constructs, BESC suggests that favourite brands play a self-defining role only for some consumers. Thus, countries higher on BESC reveal a higher tendency to include important brands as part of how they view themselves. Consequently, as 
previous studies on BESC suggested (e.g. Sprott et al., 2009), differences on BESC implicate the adaptation of suitable brand communication strategies.

\section{Cultural and economic differences in brand-related consumer behaviour}

Consumer behaviours are closely related to lifestyle and culture (Solomon et al., 2010). Growing interest in investigating cultural influences on consumer behaviour has provided much evidence supporting this thesis. Culture influences perceptions of brands (Aaker et al., 2001; Torelli et al., 2012), meanings of branded products (Strizhakova et al., 2008), and advertising effectiveness (Gould et al., 2000; Zhang and Neelankavil, 1997). Moreover, culture affects more tangible aspects of consumption, such as consumption of luxury goods (Wong and Ahuvia, 1998) or consumer responses to price information (Lalwani and Shavitt, 2013).

There has also been evidence showing how culture and economic factors shape the expressing of oneself through brands (Alserhan et al., 2015; Wallström et al., 2010). Not only consumers from individualistic cultures but also consumers from collectivist cultures use brands for self-expression (Aaker and Schmitt, 1997). They differ, however, in motivation, which pushes them to such behaviours - consumers from individualistic cultures use brands for differentiation, while consumers from collectivist cultures use them for assimilation (Aaker and Schmitt, 1997). Female consumers from India, China and the Philippines were found to perceive brands of beauty care products as more important for self-expression than female consumers from Malaysia, Japan and Australia (Wallström et al., 2010). The higher scores for expressing themselves through brands among consumers from India, China and the Philippines might be related to a greater need to manifest their financial status since these countries have experienced rapid economic growth. The self-expressive role of brands depends also on religiosity. Alserhan and co-authors (2015) extended Wallström et al.'s (2010) six-nation study to Arab women from the United Arab Emirates. The study revealed 
that the importance of brands as vehicles of self-expression for Arab women is the lowest, compared to other countries. This finding might result from Arab culture and the Islamic religion, which prohibit women from using makeup in their daily lives. Therefore, beauty care products are less important to them (Alserhan et al., 2015).

The research by Sprott's team (2009), showing the explanatory value of BESC, was conducted in the U.S., where the consumption culture has a long tradition. The first brands appeared there in the 19th century (Coca-Cola, Procter and Gamble, H. J. Heinz), and at the beginning of the 20th century, consumers were already familiar with branded products (Strizhakova et al. 2008). A cross-country study on BESC revealed that U.S. consumers reported a higher level of BESC than Korean consumers (Flynn et al., 2013). This is the only study that tested cross-country differences on BESC. It is worth mentioning that comparisons in this research were made without testing measurement invariance of the BESC scale. While calls for testing measurement invariance have been heard for almost three decades, it is still very common practice to treat instruments developed in the U.S. as universal without this analysis (Meng and Altobello Nasco, 2009). Taking into account that many multinational companies operate on international markets (Kucharska et al., 2018), there is need to explore cross-national and cross-country differences that could be used in the development of effective marketing strategies (Gürhan-Canli and Maheswaran, 2000). One of these differences is the propensity to include important brands as part of the self-concept (Sprott et al., 2009), which plays an important role in consumer behaviour.

\section{Current study: Comparisons between Austria, Italy, and Poland}

In this study, we explore differences among consumers from Austria, Italy and Poland in terms of BESC scores. Economic development and materialism as a facet of consumer lifestyle were the most important selection criteria for this study. Furthermore, the countries under study represent different cultural clusters in Europe - Italy belongs to the Latin cluster, 
Austria belongs to the Germanic cluster, and Poland represents an Eastern European country.

Despite the fact that the selected countries are members of the European Union and represent Central-European countries, they differ in many indicators associated to economic development and consumer lifestyle. As will be shown further, these variables play an important role in consumer-brand relationships. Among Austria, Italy and Poland, there are stark contrasts in a number of demographic and economic variables; e.g., with respect to population (Austria 8.7 million, Italy 60.6 million, and Poland 37.9 million) but also with respect to other areas, such as income and household consumption expenditure. In Austria the annual gross domestic product (GDP) in 2016 was higher (50 924 USD per capita) than in Italy (38 581) and Poland (27 094) (OECD, 2018).

Besides, there are significant differences related to the latest economic growth. As research indicates, consumer behaviours toward brands are affected also by this factor (Wallström et al., 2010). Due to sociopolitical reasons, Poland is a country where the branding tradition is much weaker than in Austria and Italy, and Polish consumers entered the market of branded products quite late, after the transition to a free market economy in 1989 (Lofman, 1993). Recently, Poland has experienced strong economic growth, and Polish consumers have tasted the fruits of this growth in the form of fast rising consumption (Mroz, 2010). Annual GDP per capita between 1990 to 2016 in Poland increased by 4.4 times, whereas in Austria and in Italy, it increased by 2.6 and only 2.1, respectively (OECD, 2018; Figure 1). There are also significant differences in the growth rates of household final consumption expenditure per capita. From 1995 to 2009, the growth rate of per capita consumption expenditure was $83.56 \%$ for Poland, $17.73 \%$ for Austria, and $10.58 \%$ for Italy (OECD, 2011). Poland was also the only country in the EU to avoid recession during the financial crisis (2008 - 2013) (Bogdan et al., 2015; Figure 1).The analysis of average wages also indicates strong economic growth in Poland. From 1995 to 2016, the average wages in 
Poland rose by 1.6 times, while in Austria and Italy they rose 1.3 times and 1.1 times, respectively (OECD, 2018).

Figure 1. Economic growth indicators for Austria, Italy and Poland

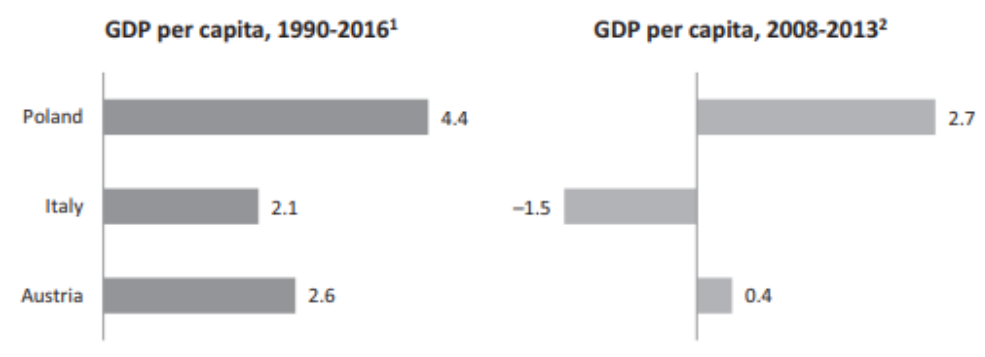

Notes: 1the ratio of GDP per capita in 2016 to GDP pre capita in 1990;

2compound annual growth rate

Another issue which is related to economic growth on one hand and which is relevant to consumer lifestyle on the other, is the level of materialism. Materialism can be defined as a set of centrally held beliefs regarding the importance of possessions of goods in one's life (Richins and Dawson, 1992). Materialism is clearly linked to spending more money (Goldsmith et al., 2014; Kasser, 2016), clothing involvement (Goldsmith et al., 2012) and such behaviours toward the brands as online brand connections (Rindfleisch et al., 2009) or brand loyalty (Podoshen and Andrzejewski, 2012). There are also several studies which showed that materialism is related to BESC (Alden et al., 2016; Sprott et al., 2009).

Materialistic consumers from the U.S. as well as from China and South Korea place greater importance on brands in terms of defining their self-concepts (Alden et al., 2016).

Materialism has been found to vary across cultures and countries (Saucier et al., 2015). An Ipsos survey (Ipsos, 2013) found that Poland represents a country with above average materialism level, whereas in Italy the level of materialism is very low (Ipsos, 2013). There are also evidences that individuals from Austria score higher on materialism compared to 
individuals from Italy (Eurobarometer, 2008). Both, economic growth of countries and level of materialism are considered here as country-level variables. The use of country-level data for economic growth and materialism is justified, because economic growth is based on objective macro-economic indicators and country's materialism comes from large representative research.

Summing up, as has been shown, the tendency to use brands for self-expression is a feature of countries that recently have experienced rapid economic growth (Wallström et al., 2010).The analysis of annual GDP per capita and average wages in studied countries indicate the largest economic growth for Poland, and the lowest for Italy (Bogdan et al., 2015; OECD, 2018). Therefore, we assume that the evidence of larger and faster economic growth in Poland is associated with a stronger propensity of Polish consumers to include brands as part of the self-concept compared to consumers in Austria and Italy. Furthermore, previous research has found evidence for a positive correlation between BESC and materialism (Alden et al., 2016; Goldsmith et al., 2012; Sprott et al., 2009). Similarly to how Poland, Austria and Italy are ranked on economic growth, the three countries also demonstrate the same order for materialism (Eurobarometer, 2008; Ipsos, 2013).These findings strengthen our assumption that consumers in the three countries under consideration also differ on levels of BESC.

Thus, based on the preceding discussion, we propose the following hypotheses:

H1. Consumers from Poland have higher levels of BESC than consumers from Austria and Italy.

H2. Consumers from Austria have higher levels of BESC than consumers from Italy.

\section{Method}

\section{Participants}


The participants came from three countries: Austria, Italy, and Poland. The total number of individuals was 1153 . Demographic characteristics of the sample by country are presented in Table 1.

Table 1. Characteristics of the sample by country

\begin{tabular}{llll}
\hline Variable & Austria & Italy & Poland \\
\hline $\mathrm{N}$ & 302 & 431 & 420 \\
Sex - male $(\%)$ & $130(43.0)$ & $157(36.4)$ & $214(51.0)$ \\
Age range & $14-67$ & n.d. & $18-72$ \\
Age $(M ; S D)$ & $27.38 ; 7.53$ & n.d. & $35.51 ; 12.15$ \\
\hline
\end{tabular}

Note: n.d. - no data available

Detailed data $(M, S D)$ on participants' age from Italy are not available due to the specifics of data collection in this country (individuals were not asked to report their exact age but to point out age range they represented). These participants ranged in age from 16 to over $40^{1}$, which means that individuals from all countries represented age-diverse groups. There were differences between Austrian and Polish samples in mean age, namely the Polish participants were older on average than the Austrian individuals $(\mathrm{t}(679.327)=-10.51, p<$ .001). Nonetheless, we did not notice a significant correlation between BESC scores and participants age in Austrian and Polish samples $(r=.025, p<.403)$, which indicates that the age will not affect the results.

\section{Measures}

Brand engagement in self-concept. We used the national versions of the Brand Engagement in Self-Concept Scale (Sprott et al., 2009). Original version of the scale (Appendix) was translated to Italian, Polish, German and then back-translated into English. The back-translation method was conducted in order to ensure that the national version of the questionnaire had the same content as the English version (Sekaran, 1983). Items were rated

\footnotetext{
${ }^{1} 22.0 \%$ participants aged $16-20 ; 43.2 \%$ - aged $21-25 ; 14.6 \%$ - aged $26-30 ; 4.6 \%$ - aged $31-35 ; 4.6 \%$ - aged 36$40 ; 10.9 \%$ - aged over 40 .
} 
on a 7-point scale, from 1 - strongly disagree to 7 - strongly agree. An overall score was computed as the sum of all eight item scores (e.g., I feel a special connection with the brands I like). High scores reflect high levels of brand engagement in self-concept.

\section{Procedure}

In all of the countries, the study was anonymous, and the participants provided informed consent before they completed questionnaires. All of the respondents were selected by convenience sampling. In Austria and Italy, the subjects were recruited via email or online social networks and were asked to fill in online questionnaire. In Poland, the participants were recruited via personal contacts of data collectors using direct solicitation. The paper-andpencil version of questionnaire was delivered to the participants and collected from them at their homes or work sites. As previous research showed, the difference in using online and paper-and-pencil questionnaires does not result in differences in response styles (de Jong et al., 2008). In Italy and Poland, participation in the study was voluntary, and the respondents did not receive any reward. In Austria (due to the practice in this country), the participants were afforded the opportunity to participate in a raffle and could win three vouchers (EUR 50 each) for the online shop Amazon.

\section{Statistical analyses}

We analysed the results using IBM SPSS Statistics software, version 22 and Mplus software, version 7.0. First, we explored missing values and descriptive statistics. Second, measurement invariance across countries was tested. We examined the factor structure of the BESC scale for each country separately. Considering the multivariate non-normality estimate, the model was tested using maximum likelihood estimation with robust standard errors (MLR). To assess the model fit, we used: Satorra-Bentler scaled chi square (S-B $\chi^{2}$ ), Root Mean Square Error of Approximation (RMSEA), Comparative Fit Index (CFI), and Standardized Root Mean Square Residual (SRMR). RMSEA and SRMR values less than .08 
and CFI values greater than .90 indicate an acceptable model fit (Schweizer, 2010). After the fit of the model was established, we used Multigroup Confirmatory Factor Analysis (MGCFA). Measurement invariance was tested by fitting a sequence of increasingly restrictive models: (1) an unconstrained model that tests whether the structure of the BESC scale is the same in all groups (configural invariance); (2) a model in which all factor loadings are equivalent across groups (metric invariance); and (3) a model assuming both factor loadings and intercepts to be equal across groups (scalar invariance) (Meredith, 1993). The increasingly restricted models were compared using the absolute difference in CFI ( $\triangle \mathrm{CFI})$. Delta CFI should be less than .01 to support measurement invariance (Cheung and Rensvold, 2002). If full measurement invariance does not hold, it is plausible to test partial invariance by sequentially relaxing equality constraints (Steenkamp and Baumgartner, 1998). To evaluate the differences in BESC among countries, we used latent mean comparison.

\section{Results}

\section{Preliminary analyses}

There were no missing data in the BESC scale items. The descriptive statistics, including means, standard deviations, skewness, kurtosis, and internal consistency, are presented in Table 2 .

Table 2. Means, standard deviations, skewness, kurtosis, and internal consistency of BESC across countries

\begin{tabular}{lcccccc}
\hline Country & Range & $\boldsymbol{M}$ & $\boldsymbol{S} \boldsymbol{D}$ & Skewness & Kurtosis & $\boldsymbol{\alpha}$ \\
\hline Austria & $8-56$ & 21.24 & 11.78 & 0.62 & -0.60 & .96 \\
Italy & $8-56$ & 18.41 & 10.93 & 1.27 & 1.02 & .96 \\
Poland & $8-53$ & 22.68 & 10.31 & 0.48 & 0.60 & .93 \\
\hline
\end{tabular}

BESC scores indicate adequate internal consistency in all studied countries. The range of obtained results was comparable between the countries. In each country BESC scores showed a positively skewed distribution. Even the highest score was observed in Italian 
sample, skewness and kurtosis did not exceed the critical limits for any of the total scales (Kline, 2005), indicating that no scale had to be transformed.

\section{Cross-country scale validation: Measurement invariance of BESC scale}

We tested a single-factor CFA model of BESC in each sample. Models in which measurement errors of individual items were not correlated do not fully fit the data in any of the samples: Austria $\left(\mathrm{S}-\mathrm{B} \chi^{2}(20)=80.381, p<.001, \mathrm{CFI}=.954, \mathrm{RMSEA}=.100\right.$ with $90 \% \mathrm{CI}$ $=.078-.123, \mathrm{SRMR}=.035) ;$ Italy $\left(\mathrm{S}-\mathrm{B} \chi^{2}(20)=108.043, p<.001, \mathrm{CFI}=.949, \mathrm{RMSEA}=\right.$ .101 with $90 \% \mathrm{CI}=.083-.120, \mathrm{SRMR}=.033)$; and Poland $\left(\mathrm{S}-\mathrm{B} \chi^{2}(20)=106.632, p<.001\right.$, $\mathrm{CFI}=.952, \mathrm{RMSEA}=.102$ with $90 \% \mathrm{CI}=.083-.121, \mathrm{SRMR}=.038)$. Previously, it was shown that measurement errors between Item 1 and Item 2 and between Item 7 and Item 8 could be correlated (Razmus and Laguna, 2019). Based on this finding, we inspected the modification indices in all of the samples. They confirmed previous research on BESC scale structure, and we specified the second model. This model turned out to fit the data well in each sample (Table 3). All factor loadings for items in each country were significant and ranged from .51 to .91(Appendix). Having determined a baseline model for each subsample, MGCFA was performed. The analysis revealed that configural and metric invariance across countries was obtained (Table 3). Scalar invariance was not established because the drop in CFI exceeded the recommended threshold $(\Delta C F I=.014)$. Subsequently, the model was tested for partial scalar measurement invariance freeing intercepts with the largest misspecifications. When the intercept for Item 2 in the Austrian sample and the intercept for Item 5 in the Italian sample were allowed to vary, partial scalar invariance was achieved (Table 3). 
Table 3. BESC measurement invariance across countries

\begin{tabular}{lcccccccc}
\hline Models & S-B $\chi^{2}$ & $d f$ & $p$ & RMSEA & SRMR & CFI & $\begin{array}{c}\text { Model } \\
\text { Comparison }\end{array}$ & $\Delta$ CFI \\
\hline Austria & 52.476 & 18 & .001 & .080 & .026 & .974 & & \\
Italy & 54.647 & 18 & .001 & .069 & .020 & .979 & & \\
Poland & 46.064 & 18 & .001 & .061 & .024 & .984 & & - \\
M1. Configural invariance & 166.781 & 54 & .001 & .074 & .023 & .977 & - & .006 \\
M2. Metric invariance & 214.543 & 70 & .001 & .073 & .064 & .971 & M2 vs M1 & .014 \\
M3. Scalar invariance & 299.664 & 86 & .001 & .081 & .123 & .957 & M3 vs M2 & .014 \\
M4. Partial scalar & 280.653 & 84 & .001 & .078 & .121 & .961 & M4 vs M2 & .010 \\
invariance & & & & & & & & \\
\hline
\end{tabular}

Note. S-B $\chi^{2}$ - Satorra-Bentler scaled chi square; df - degrees of freedom; RMSEA - Root Mean Square Error of Approximation; CFI - Comparative Fit Index; SRMR - Standardized Root Mean Square Residual.

$\Delta$ CFI less than .01 indicates measurement invariance.

\section{Differences in BESC among countries: Latent mean comparisons}

To evaluate the significance of the latent mean differences in BESC among countries, we used the parameters of the last model. The results showed that consumers from Italy had a significantly lower mean than consumers from Austria (-0.258 units, $\mathrm{SE}=0.093, p=.006, \mathrm{~d}=$ $0.25)$ and consumers from Poland (-0.505 units, $\mathrm{SE}=0.076, p<.001, \mathrm{~d}=0.40)$. Additionally, consumers from Poland scored higher than consumers from Austria (0.413 units, $\mathrm{SE}=0.095$, $p<.001, \mathrm{~d}=0.13)$. The results provide support for hypothesis 1 , that assumed that consumers from Poland have higher levels of BESC than consumers from Austria and Italy. Moreover, consumers from Austria report higher levels of BESC than consumers from Italy, which corroborates hypothesis 2 .

\section{Discussion}

The aim of the present study was to investigate cross-country differences in BESC, assessed with the BESC scale, among consumers from three European countries: Austria, Italy, and Poland. Before the comparison was undertaken, measurement invariance of the 
scale across the three countries was tested. The results provided evidence for partial scalar measurement invariance, allowing for appropriate cross-group comparisons (Steenkamp and Baumgartner, 1998). It is not surprising, as partial scalar invariance is a frequent result in measurement invariance studies (Putnick and Bornstein, 2016). Our results showed that Polish consumers scored higher on BESC than consumers from Austria and Italy. In addition, consumers from Austria obtained higher results on BESC than consumers from Italy. Our findings support the idea that consumer-brand relationships could be associated with rapid economic growth. In particular, the study results corroborate Wallström and colleagues' (2010) research, which indicated that expressing oneself through brands is specific for consumers in economically growing countries. The findings also seem to be consistent with Flynn, Goldsmith and Korzenny (2011), who argued that, because consumers are exposed to increasing levels of marketing influence as their economy grows, their new purchasing power and access to branded goods might stimulate increasing use of brands as the means of selfidentification. The observed cross-country differences are in line with the results of studies on materialism, in which materialism has been found to be positively correlated with BESC (Alden et al., 2016; Sprott et al., 2009). Still, it is important to distinguish between BESC and materialism. As Goldsmith et al. (2012) point out, BESC is related to the acquisition of specific, branded goods that embody one or more important elements of the self, whereas materialism involves acquiring possessions in general.

In light of these results, this paper contributes to the branding and the cross-country literature both in terms of theory and practice. From a theoretical point of view, this paper contributes to the branding literature by providing further explanation of the concept of brand engagement in self-concept and brand identification adopting a cross-country perspective. Particularly, we found that BESC, defined as an individual tendency to include important brands as part of the self-concept, depends on socio-economic determinants. Therefore, BESC 
is not a characteristic that is immutable and unaffected by experience or circumstances. BESC may be changeable due to social and economic settings in the countries. Thus, these findings help researchers understand BESC phenomenon and further develop its theoretical framework. Moreover, the paper provides evidence that consumer behaviours related to the aspect of identification with brands may depend on the country context. From the global perspective, it is critically important to understand how consumers from different countries concentrate on brands in relation to the self. Our research recognizes that consumers from the youngest market, Poland, have the strongest tendency to create self schemas related to important brands. These consumers are the most sensitized to brands in relation to the self. Interestingly, consumers from Italy are characterized by the lowest level of propensity to include important brands as part of the self-concept.

This research contributes also to the literature on BESC from a methodological point of view. Indeed, the BESC, as measured by the BESC scale, can be considered universal across the nations included in this study. Certainly, some of the items showed cultural differences (items for which intercepts were not invariant), but full scalar invariance is very difficult to establish (Steinmetz, 2011). In the earlier cross-country studies on BESC, measurement equivalence was not investigated (Flynn et al., 2013).

From a managerial point of view, this research has also practical implications for brand management. The knowledge generated from this study reinforces the importance of managing the relationship with the brand. Specifically, the results suggest that cross-country differences in BESC should be understood by international firms by respecting the specificity of consumer-brand relationships and providing additional information for the development of suitable brand communication strategies in each country. Using the BESC scale helps global marketing managers better understand how consumers in a given country attribute meanings to branded products. This is especially useful for managers who want to enter a new country 
market and adapt their brand communication strategy accordingly. In country markets where many consumers seem to have a higher tendency to use brands to express and confirm their identities - such as Poland - managers should actively plan how to incorporate their brands as part of high-BESC consumers' self-concepts and how to prevent competing brands from building such connections (Sprott et al., 2009). Brand communication should project an imaginary identity that individuals want to achieve by the adoption of the specific brand, a strategy that might be easier to implement for products that provide hedonic and symbolic benefits. In target markets where many consumers might be less prone to use important brands as part of how they view themselves - such as Italy - managers should, among other things, take into account that the perspectives and opinions of other brand users have been found to be very important to connect low-BESC consumers with the brand (Palazon et al., 2019). To sum up, considering whether a brand's target markets are lower or higher in BESC may benefit international firms and, in addition to other relevant criteria, help them to adapt brand communication strategies accordingly (see also Sprott et al., 2009).

\section{Future research and limitations}

As with all research efforts, this study is not free of limitations. First, we focused on only three European national markets, which means that the results relate only to these countries and cannot be generalized to other markets. Generalizability to countries beyond the three studied here should be investigated. In future research it is worth considering not only European countries, but also United States, Australia and New Zealand. Second, the study was based on data from convenience samples which is a common methodological solution in many scientific researches. This technique of sampling has limitations in terms of representation and bias. Given that this research was the first to investigate cross-country differences in BESC after providing evidence for measurement invariance of the BESC scale, we encourage future efforts to replicate these results using representative samples from more 
countries. Third, our study focused only on cross-country differences in BESC, so future research is needed to evaluate cross-country differences concerning psychological or marketing antecedents and consequences of BESC, that could better explain motivations at the basis of BESC cross-country differences and consequences of BESC dissimilarities. Our conceptual focus is on materialism and economic growth. However, it is possible that other consumption-related factors (e.g., hedonism, individualism) may similarly encourage (or discourage) consumers to engage brands in self concepts. Likewise, future research could broaden our findings by examining the degree to which insecurity could influence consumers' BESC. Indeed, literature suggests that secure relationship attachments (Arndt et al., 2004), offer protection from existential fears; in this vein, insecurity could affect the propensity of individuals to engage brands in their concept. Since traditional sources of security are family, community, and religion (Rindfleisch et al., 2009), security and thus BESC could change depending on the country culture.

\section{Appendix}

Scale items used to measure BESC

Factor loadings

Items

1. I have a special bond with the brands that I like $\begin{array}{lll}.76 & .68 & .51\end{array}$

2. I consider my favorite brands to be a part of myself $\begin{array}{lll}.87 \quad .85 & .81\end{array}$

3. I often feel a personal connection between my brands and me $\begin{array}{lll}.92 & .89 & .80\end{array}$

4. Part of me is defined by important brands in my life $\begin{array}{lll}86 & .93 & .88\end{array}$

5. I feel as if I have a close personal connection with the brands I most prefer

6. I can identify with important brands in my life $\begin{array}{lll}.91 & .93 & .90\end{array}$

7. There are links between the brands that I prefer and how I view myself $\begin{array}{lll}.91 & .87 & .83\end{array}$

8. My favorite brands are an important indication of who I am $\begin{array}{lll}.82 & .84 & .81\end{array}$ $\begin{array}{lll}.81 & .83 & .85\end{array}$

$\begin{array}{llll}\text { AVE } & .74 & .73 & .65\end{array}$




\section{Conflict of interest}

On behalf of all authors, the corresponding author states that there is no conflict of interest. 


\section{References}

Aaker, J.L., Benet-Martínez, V. and Garolera, J. (2001), “Consumption symbols as carriers of culture: A study of Japanese and Spanish brand personality constructs", Journal of Personality \& Social Psychology, Vol. 81 No. 3, pp. 492-508.

Aaker, J.L., Fournier, S. and Brasel, S.A. (2004), "When good brands do bad", Journal of Consumer Research, Vol. 31 No. 1, pp. 1-16.

Aaker, J.L. and Schmitt, B. (1997), The Influence of Culture on the Self-Expressive Use of Brands, No. Working Paper no. 274, UCLA Anderson Graduate School of Management.

Alden, D.L., Kelley, J.B., Youn, J.B. and Chen, Q. (2016), “Understanding consumer motivations to interact on brand websites in the international marketplace: Evidence from the U.S., China, and South Korea”, Journal of Business Research, Vol. 69 No. 12, pp. 5909-5916.

Alserhan, B.A., Halkias, D., Boulanouar, A.W., Dayan, M. and Alserhan, O.A. (2015), "Expressing herself through brands: The Arab woman's perspective", Journal of Research in Marketing and Entrepreneurship, Vol. 17 No. 1, pp. 36-53.

Arndt, J., Solomon, S., Kasser, T. and Sheldon, K.M. (2004), “The urge to splurge: A terror management account of materialism and consumer behavior", Journal of Consumer Psychology, Vol. 14 No. 3, pp. 198-212.

Batra, R., Ahuvia, A. and Bagozzi, R.P. (2012), "Brand love”, Journal of Marketing, Vol. 76 No. 2, pp. 1-16.

Bogdan, W., Boniecki, D., Labaye, E., Marciniak, T. and Nowicki, M. (2015), Poland 2025: Europe's New Growth Engine, McKinsley \& Company, Boston, MA. 
Brodie, R.J., Hollebeek, L.D., Jurić, B. and Ilić, A. (2011), “Customer engagement: Conceptual domain, fundamental propositions, and implications for research", Journal of Service Research, Vol. 14 No. 3, pp. 252-271.

Cheung, G.W. and Rensvold, R.B. (2002), "Evaluating goodness-of-fit indexes for testing measurement invariance”, Structural Equation Modeling, Vol. 9 No. 2, pp. 233-255.

Escalas, J.E. (2004), "Narrative processing: Building consumer connections to brands", Journal of Consumer Psychology, Vol. 14 No. 1-2, pp. 168-180.

Escalas, J.E. and Bettman, J.R. (2003), "You are what they eat: The influence of reference groups on consumers' connections to brands", Journal of Consumer Psychology, Vol. 13 No. 3, pp. 339-348.

Eurobarometer. (2008), Values of Europeans, Brussels, Belgium: European Commission Directorate.

Ferraro, R., Escalas, J.E. and Bettman, J.R. (2011), “Our possessions, our selves: Domains of self-worth and the possession-self link”, Journal of Consumer Psychology, Vol. 21 No. 2, pp. 169-177.

Fetscherin, M. and Heinrich, D. (2015), “Consumer brand relationships research: A bibliometric citation meta-analysis", Journal of Business Research, Vol. 68 No. 2, pp. $380-390$.

Flynn, L.R., Goldsmith, R.E. and Korzenny, F. (2011), "Brand engagement in self-concept: A psychometric and demographic analysis", Journal of Multidisciplinary Research, Vol. 3 No. 2, pp. 5-18.

Flynn, L.R., Goldsmith, R.E. and Pollitte, W. (2016), "Materialism, status consumption, and market involved consumers", Psychology \& Marketing, Vol. 33 No. 9, pp. 761-776. 
Flynn, L.R., Goldsmith, R.E. and Wan-Min Kim. (2013), “A cross-cultural study of materialism and brand engagement", Journal of Multidisciplinary Research, Vol. 5 No. 3, pp. 49-69.

Fournier, S. (1998), “Consumers and their brands: Developing relationship theory in consumer research", Journal of Consumer Research, Vol. 24 No. 4, pp. 343-373.

Goldsmith, R.E., Flynn, L.R. and Clark, R.A. (2011), "Materialism and brand engagement as shopping motivations", Journal of Retailing \& Consumer Services, Vol. 18 No. 4, pp. $278-284$.

Goldsmith, R.E., Flynn, L.R. and Clark, R.A. (2012), "Materialistic, brand engaged and status consuming consumers and clothing behaviors", Journal of Fashion Marketing \& Management, Vol. 16 No. 1, pp. 102-119.

Goldsmith, R.E., Flynn, L.R. and Clark, R.A. (2014), “The etiology of the frugal consumer”, Journal of Retailing \& Consumer Services, Vol. 21 No. 2, pp. 175-184.

Gould, S.J., Gupta, P.B. and Grabner-Kräuter, S. (2000), "Product placements in movies: A cross-cultural analysis of Austrian, French and American consumers' attitudes toward this emerging, international promotional medium", Journal of Advertising, Vol. 29 No. 4, pp. 41-58.

Gürhan-Canli, Z. and Maheswaran, D. (2000), "Cultural variations in country of origin effects", Journal of Marketing Research, Vol. 37 No. 3, pp. 309-317.

Hakala, U., Svensson, J. and Vincze, Z. (2012), “Consumer-based brand equity and top-ofmind awareness: A cross-country analysis", Journal of Product \& Brand Management, Vol. 21 No. 6, pp. 439-451.

Hollebeek, L. (2011), “Demystifying customer brand engagement: Exploring the loyalty nexus", Journal of Marketing Management, Vol. 27 No. 7/8, pp. 785-807. 
Ipsos. (2013), "Global attitudes on materialism, finances and family”, available at:

https://www.ipsos.com/en-us/news-polls/global-attitudes-materialism-finances-andfamily (accessed 10 February 2018).

Islam, J.U. and Rahman, Z. (2016), “The transpiring journey of customer engagement research in marketing”, Management Decision, Vol. 54 No. 8, pp. 2008-2034.

Jakubanecs, A., Supphellen, M., Haugen, H.M. and Sivertstøl, N. (2019), “Developing brand emotions across cultures: Effects of self-construal and context", Journal of Consumer Marketing, Vol. 36 No. 4, pp. 472-483.

Jamal, A. and Goode, M.M.H. (2001), “Consumers and brands: A study of the impact of selfimage congruence on brand preference and satisfaction”, Marketing Intelligence \& Planning, Emerald Group Publishing Limited, Vol. 19 No. 7, pp. 482-492.

de Jong, M.G., Steenkamp, J.-B.E.M., Fox, J.-P. and Baumgartner, H. (2008), “Using Item Response Theory to measure extreme response style in marketing research: A global investigation", Journal of Marketing Research, Vol. 45 No. 1, pp. 104-115.

Kasser, T. (2016), “Materialistic values and goals”, Annual Review of Psychology, Vol. 67 No. 1, pp. 489-514.

Keller, K.L. (1993), “Conceptualizing, measuring, managing customer-based brand equity”, Journal of Marketing, Vol. 57 No. 1, pp. 1-22.

Kline, R.B. (2005), Principles and Practices of Structural Equation Modeling (2nd Ed.), Guilford Press, New York.

Kucharska, W., Flisikowski, K. and Confente, I. (2018), "Do global brands contribute to the economy of their country of origin? A dynamic spatial approach”, Journal of Product \& Brand Management, Vol. 27 No. 7, pp. 768-780.

Lalwani, A.K. and Shavitt, S. (2013), "You get what you pay for? Self-construal influences price-quality judgments", Journal of Consumer Research, Vol. 40 No. 2, pp. 255-267. 
Lisjak, M., Lee, A.Y. and Gardner, W.L. (2012), "When a threat to the brand is a threat to the self: The importance of brand identification and implicit self-esteem in predicting defensiveness", Personality and Social Psychology Bulletin, Vol. 38 No. 9, pp. 11201132.

Liu, R.L. and Minton, E.A. (2018), "Faith-filled brands: The interplay of religious branding and brand engagement in the self-concept", Journal of Retailing and Consumer Services, Vol. 44, pp. 305-314.

Liu, R.L., Sprott, D.E., Spangenberg, E.R., Czellar, S. and Voss, K.E. (2018), “Consumer preference for national vs. private brands: The influence of brand engagement and self-concept threat”, Journal of Retailing \& Consumer Services, Vol. 41, pp. 90-100.

Lofman, B. (1993), “Consumers in rapid transition: The Polish experience”, in McAlister, L. and Rothschild, M. (Eds.), Advances in Consumer Research, Vol. 20, Association for Consumer Research, Provo, UT, pp. 18-22.

Markus, H. (1977), "Self-schemata and processing information about the self”, Journal of Personality and Social Psychology, Vol. 35 No. 2, pp. 63-78.

Markus, H.R. and Kitayama, S. (1991), “Culture and the self: Implications for cognition, emotion, and motivation", Psychological Review, Vol. 98 No. 2, pp. 224-253.

Markus, H.R. and Kitayama, S. (2010), “Cultures and selves: A cycle of mutual constitution”, Perspectives on Psychological Science, Vol. 5 No. 4, pp. 420-430.

Mazzoli, V., Acuti, D., Donvito, R. and Ko, E. (2019), "Dressing your soul: The role of brand engagement in self-concept", Mercati e Competitivit, FrancoAngeli Editore, Vol. 1 No. 1, pp. $75-102$.

Meng, J. and Altobello Nasco, S. (2009), “Cross-cultural equivalence of price perceptions across American, Chinese, and Japanese consumers", Journal of Product \& Brand Management, Vol. 18 No. 7, pp. 506-516. 
Meredith, W. (1993), "Measurement invariance, factor analysis and factorial invariance”, Psychometrika, Vol. 58 No. 4, pp. 525-543.

Mroz, B. (2010), “Consumerism vs. sustainability: The emergence of new consumer trends in Poland”, International Journal of Economic Policy in Emerging Economies, Vol. 3 No. 1, pp. 1-15.

MSI. (2010), Marketing Science Institute. 2010-2012 Research Priorities, available at: http:// www.msi.org/pdf/MSI_RP10-12.pdf (accessed 16 February 2017).

OECD. (2011), OECD Data, available at: https://data.oecd.org (accessed 23 August 2018).

OECD. (2018), OECD Data, available at: https://data.oecd.org (accessed 23 August 2018).

Palazon, M., Delgado-Ballester, E. and Sicilia, M. (2019), "Fostering brand love in Facebook brand pages", Online Information Review, Vol. 43 No. 5, pp. 710-727.

Podoshen, J.S. and Andrzejewski, S.A. (2012), “An examination of the relationships between materialism, conspicuous consumption, impulse buying, and brand loyalty", Journal of Marketing Theory \& Practice, Vol. 20 No. 3, pp. 319-334.

Putnick, D.L. and Bornstein, M.H. (2016), “Measurement invariance conventions and reporting: The state of the art and future directions for psychological research", Developmental Review, Vol. 41, pp. 71-90.

Razmus, W., Jaroszyńska, M. and Palęga, M. (2017), “Personal aspirations and brand engagement in self-concept", Personality and Individual Differences, Vol. 105, pp. 294-299.

Razmus, W. and Laguna, M. (2019), "Brand engagement in Self-concept: Scale properties and the global nature of the construct", Current Psychology, No. 38, pp. 1-7.

Reimann, M., Castaño, R., Zaichkowsky, J. and Bechara, A. (2012), "How we relate to brands: Psychological and neurophysiological insights into consumer-brand relationships", Journal of Consumer Psychology, Vol. 22 No. 1, pp. 128-142. 
Richins, M.L. and Dawson, S. (1992), “A consumer values orientation for materialism and its measurement: Scale development and validation", Journal of Consumer Research, Vol. 19 No. 3, pp. 303-316.

Rindfleisch, A., Burroughs, J.E. and Wong, N. (2009), “The safety of objects: Materialism, existential insecurity, and brand connection”, Journal of Consumer Research, Vol. 36 No. 1, pp. 1-16.

Samala, N. and Singh, S. (2018), "Millennial's engagement with fashion brands: A moderated-mediation model of brand engagement with self-concept, involvement and knowledge”, Journal of Fashion Marketing and Management, Vol. 23 No. 1, pp. 216.

Saucier, G., Kenner, J., Iurino, K., Malham, P.B., Chen, Z., Thalmayer, A.G., Kemmelmeier, M., et al. (2015), "Cross-cultural differences in a global 'Survey of World Views"”, Journal of Cross-Cultural Psychology, Vol. 46 No. 1, pp. 53-70.

Schweizer, K. (2010), "Some guidelines concerning the modeling of traits and abilities in test construction”, European Journal of Psychological Assessment, Vol. 26 No. 1, pp. 1-2.

Sekaran, U. (1983), "Methodological and theoretical issues and advancements in crosscultural research”, Journal of International Business Studies, Vol. 14 No. 2, pp. 6173.

Solomon, M., Bamossy, G., Askegaard, S. and Hogg, M.K. (2010), Consumer Behaviour: A European Perspective, 4 edition., Prentice Hall Ptr, New York.

Sprott, D., Czellar, S. and Spangenberg, E. (2009), “The importance of a general measure of brand engagement on market behavior: Development and validation of a scale”, Journal of Marketing Research, Vol. 46 No. 1, pp. 92-104. 
Steenkamp, J.-B.E.M. and Baumgartner, H. (1998), “Assessing measurement invariance in cross-national consumer research", Journal of Consumer Research, Vol. 25 No. 1, pp. 78-90.

Steinmetz, H. (2011), "Estimation and comparison of latent means across cultures", in Davidov, E., Schmidt, P. and Billiet, J. (Eds.), Cross-Cultural Analysis: Methods and Applications., Routledge/Taylor \& Francis Group, New York, NY, pp. 85-116.

Stokburger-Sauer, N., Ratneshwar, S. and Sen, S. (2012), "Drivers of consumer-brand identification”, International Journal of Research in Marketing, Vol. 29 No. 4, pp. 406-418.

Strizhakova, Y., Coulter, R.A. and Price, L.L. (2008), "The meanings of branded products: A cross-national scale development and meaning assessment", International Journal of Research in Marketing, Vol. 25 No. 2, pp. 82-93.

Strizhakova, Y., Coulter, R.A. and Price, L.L. (2011), "Branding in a global marketplace: The mediating effects of quality and self-identity brand signals", International Journal of Research in Marketing, Vol. 28 No. 4, pp. 342-351.

Tan, T.M., Salo, J., Juntunen, J. and Kumar, A. (2019), “The role of temporal focus and selfcongruence on consumer preference and willingness to pay", European Journal of Marketing, Vol. 53 No. 1, pp. 37-62.

Torelli, C.J., Özsomer, A., Carvalho, S.W., Keh, H.T. and Maehle, N. (2012), “Brand concepts as representations of human values: Do cultural congruity and compatibility between values matter?", Journal of Marketing, Vol. 76 No. 4, pp. 92-108.

Wallström, Å., Steyn, P. and Pitt, L. (2010), "Expressing herself through brands: A comparative study of women in six Asia-Pacific nations", Journal of Brand Management, Vol. 18 No. 3, pp. 228-237. 
Whan Park, C., MacInnis, D.J., Priester, J., Eisingerich, A.B. and Iacobucci, D. (2010), "Brand attachment and brand attitude strength: Conceptual and empirical differentiation of two critical brand equity drivers", Journal of Marketing, Vol. 74 No. 6, pp. 1-17.

Wong, N.Y. and Ahuvia, A.C. (1998), "Personal taste and family face: Luxury consumption in confucian and western societies", Psychology \& Marketing, Vol. 15 No. 5, pp. 423441.

Zhang, Y. and Neelankavil, J.P. (1997), “The influence of culture on advertising effectiveness in China and the USA", European Journal of Marketing, Vol. 31 No. 1/2, pp. 134149. 